\title{
Primary squamous cell carcinoma of the stomach
}

\author{
Osman Bilgin Gülçiçek ${ }^{1}$, Ali Solmaz¹, Kamil Özdoğan¹, Candaș Erçetin¹, Erkan Yavuz', Hakan Yiğitbaș', Fatih Çelebi', \\ Serdar Altınay ${ }^{2}$
}

\section{ABSTRACT}

'Clinic of General Surgery, Bağcilar Training and Research Hospital, İstanbul, Turkey

${ }^{2}$ Clinic of Pathology, Bağcilar Training and Research Hospital, İstanbul, Turkey

Address for Correspondence Ali Solmaz e-mail: solmazali@hotmail.com

Received: 07.07.2014

Accepted: 20.09.2014

Available Online Date : 19.06.2015

(C) Copyright 2016 by Turkish Surgical Association

Available online at www.ulusalcerrahidergisi.org
Primary squamous cell carcinoma of the stomach accounts for less than $1 \%$ of all gastric malignancies. Less than 100 cases were reported in the literature. Therefore, knowledge about management and prognosis of the disease is limited. Surgical approach is the basic form of treatment. In this study we confirmed a case of primary gastric squamous cell carcinoma with the aim of contribution to the literature, which is seen rare, and the diagnosis was confirmed pathologically.

Keywords: Squamous cell carcinoma, stomach, pathology

\section{INTRODUCTION}

Adenocarcinoma accounts for $95 \%$ of primary gastric carcinomas. The incidence of primary squamous cell carcinoma (SCC) of the stomach is less than $1 \%$ of all gastric malignancies (1). It is first described by Rörig et al. in 1895 (2, 3). It is more commonly seen in men and incidence increase in sixth decade $(2,3)$. Squamous cell carcinoma of the stomach is not involved in the formation of Lauren and World Health Organisation (WHO) classification of gastric cancer. Squamous cell carcinoma may arise from tertiary syphilis, corrosive acid intake and prolonged cyclophosphamide treatment. These tumors may originate from undifferentiated mucosal stem cell that arise from squamous metaplasia and ectopic squamous epithelial background (4). Here we present an unusual case of primary gastric squamous cell carcinoma.

\section{CASE PRESENTATION}

Forty-nine years old man applied to our clinic with the symptoms of nausea, vomiting and epigastric pain. The patient had a history of $4 \mathrm{~kg}$ weight loss in last three months. His sister had died because of gastric cancer. The patient's physical examination was unremarkable. Laboratory tests were normal, except anemia ( $\mathrm{Hgb}: 7.2 \mathrm{~g} / \mathrm{dL}$ ). There was a prepyloric antral wall thickening and multiple lymphadenopathy around celiac trunk, hepatoduodenal ligament and perigastric area. Then, we made an endoscopy to the patient. In endoscopy there was an ulcerovegetative mass from antrum toward pylorus (Figure 1). Pathology result was squamous cell carcinoma. There was no adenoid component. The patient was taken for screening whole-body positron emission tomography (PET). We saw irregular wall-thickening and mass lesion that has intense fluorodeoxyglucose (FDG) standardised uptake value (SUVmax: 20.3). Besides that there were multiple lymph nodes around lesser curvature, gastroduodenal area and hepatic hilus which have less FDG uptake (SUVmax:3.4). The patient was operated on July 2013, there was a tumoral mass of $10 \times 5 \mathrm{~cm}$ involving all layers of gastric wall. Total gatrectomy and Roux-en-Y esophagojejunostomy (D2 dissection) were done. The patient was discharged after $7^{\text {th }}$ day of the operation.

Specimen including stomach, omentum and lymph nodes was sent for histopathologic examination. When the incision through lesser curvature was done there was an ulcerovegetative mass located on posterior antral wall which has $6 \mathrm{~cm}$ proximal and $1.8 \mathrm{~cm}$ distal margin (Figure 2). Macroscopically the tumor has reached serosal layer.

Microscopic examination of tumoral area revealed that there were atypical bizarre epithelial cells including keratin plugs with eosinophilic cytoplasms, prominent nucleoli and intercellular bridges. These findings resemble us squamous cell carcinoma of other parts of the body. Examined numerous samples did not prove adenoid component. The tumor cells were stained strongly positive by p63, CK 5/6 and CK7 immunohistochemically, that means squamous neoplasia (Figure 3).

Tumor was extending into the subserosal layer. There was no invasion in perigastric, paraaortic, celiac mesenteric lymph nodes, but 5 of the regional lymph nodes were invaded. Proximal and distal surgical margins were clear. There was a widespread intestinal metaplasia around the tumor. The tumor was accepted as pT3N2 according to the TNM classification. 


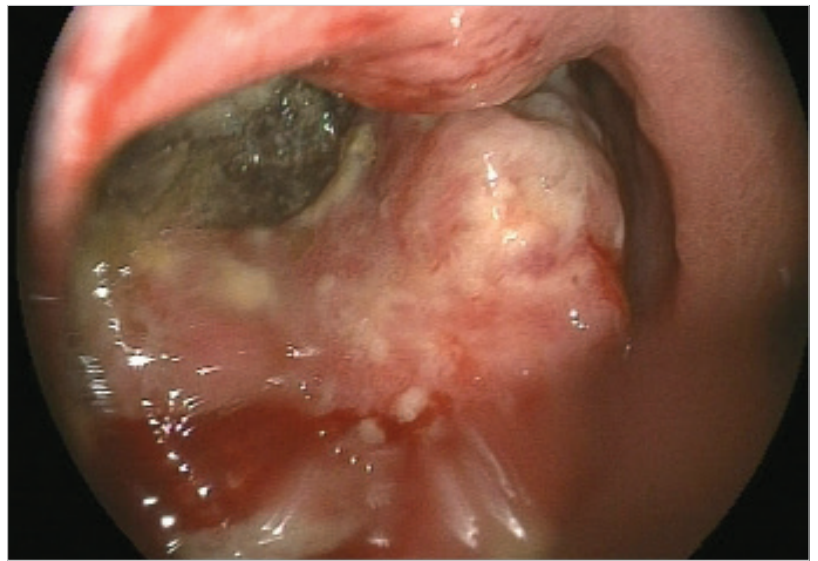

Figure 1. Endoscopic appearance of the tumor

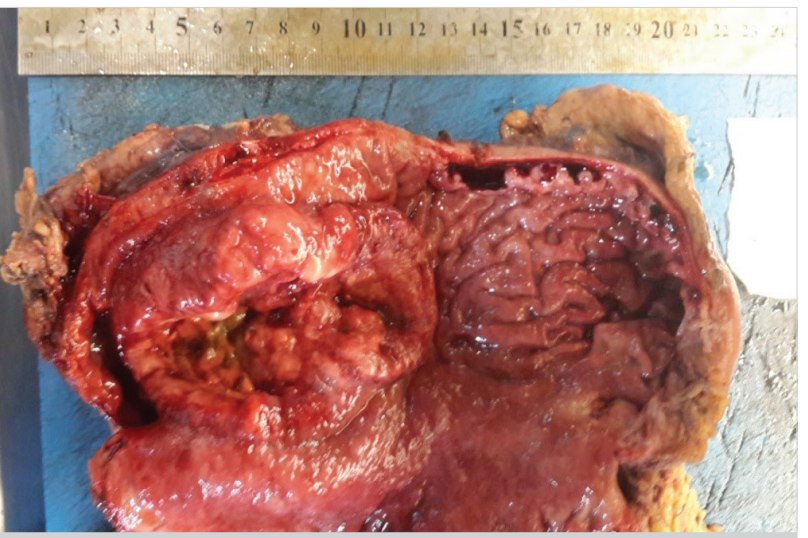

Figure 2. Macroscopic appearance of the tumor. Stomach is incised through lesser curvature.

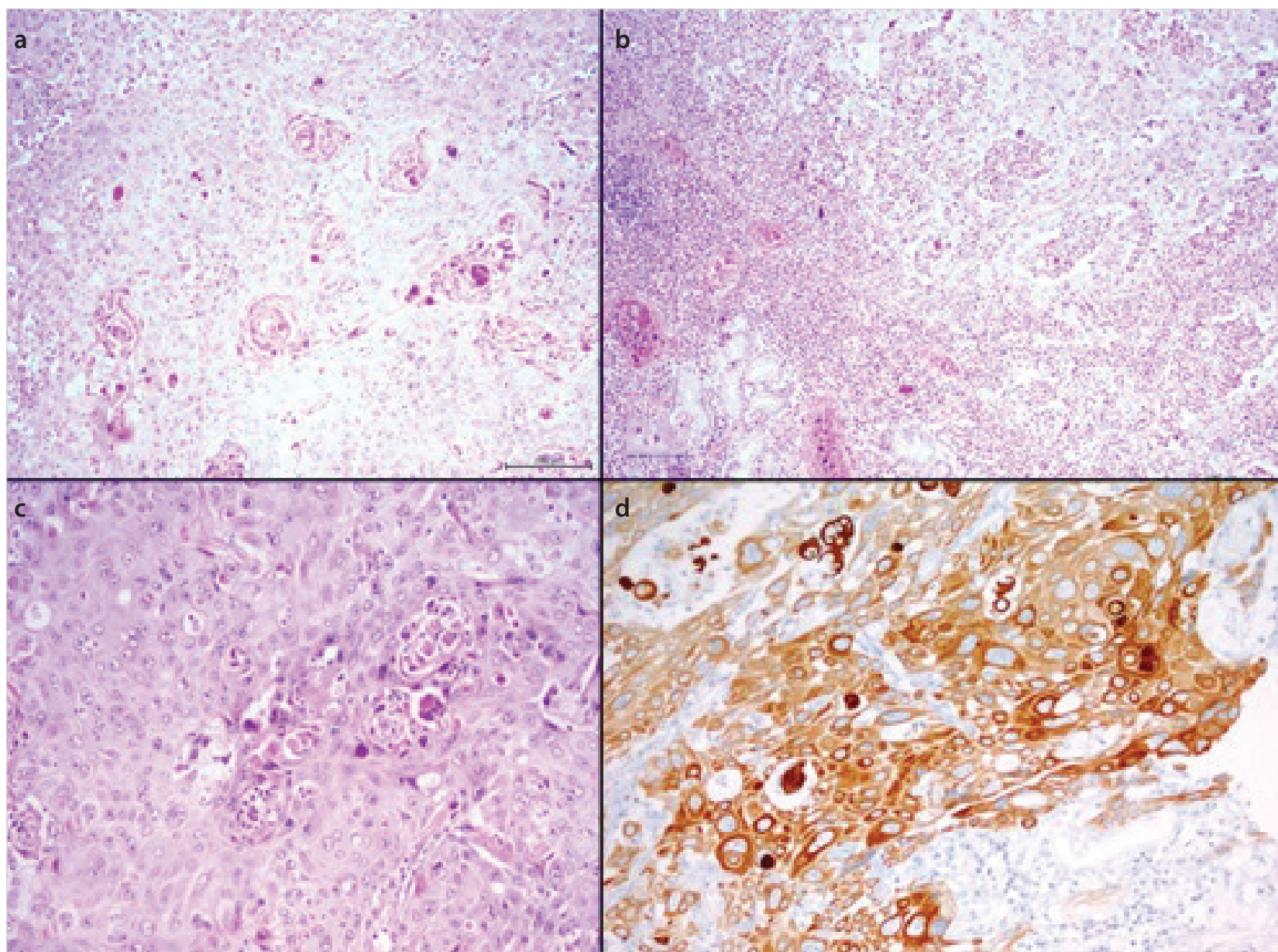

Figure 3. a-d. Neoplastic cell infiltration next to the gastric cells (x10) (a). Keratin plugs supporting squamous neoplasia (b). Atypical squamous epithelial cells with eosinophilic cytoplasm with large, prominent nucleoli (c). Tumor cells displayed (d) CK5/6 immunoreactivity. A;X10, B;X10, C;X20 (H\&E). D;X20 (CK5/6)

A month after the operation the patient was taken to the oncological treatment program. Cisplatin $\left(60 \mathrm{mg} / \mathrm{m}^{2} /\right.$ day $)$ one dose and capecitabine ( $2000 \mathrm{mg} / \mathrm{m}^{2} /$ day) 14 day combination chemotherapy was administered. After chemotherapy, 45 Gy in 25 fraction radiotherapy and capecitabine (1650 mg/m²/day) were applied concurrently. This protocol was administered 5 days a week for 5 weeks. Than initial chemoterapy was repeated, thus oncological treatment

\section{DISCUSSION}

Primary gastric squamous cell carcinoma (SCC) accounts 0.04$0.07 \%$ of of all gastric malignancies. It is first descibed by Rörig et al. in $1895(2,3)$. Since then only about 100 cases have been published (4). It is five times more common in males. When compared to adenocarcinoma, it is more aggressive and more prone to make lymphovascular invasion (5). For the diagnosis of gastric squamous cell carcinoma, the tumor must be completely in gastric mucosa and the esophageal mucosa should be spare of the tumor. For this reason Parks et al. (6) described 
3 criteria for the diagnosis: 1) The tumor should not be localized in cardia. 2) The tumor should not invade esophagus. 3) The tumor should not be elsewhere in the body. Beside these criteria Boswell and Helwig (7) had defined 4 histopathological criteria: 1) Keratinized cell masses lined up like pearls. 2) Mosaic pattern cells that have sharp scheme. 3) Intercellular bridges (In high concentration sulphydril and disulfide groups) 4) Containing keratin.

There are some processes for the explanation of pathophysiology of primary SCC of the stomach. Most popular of them is malignant transformation from squamous metaplastic background. SCC is associated with chronic inflammation in the absence of metaplasia (8). Outside of these processes have been reported by Strauss et al. (9): 1) Squamous differentiation in adenocarcinoma. 2) Squamous metaplasia in endothelial cells or gastric vessels. 3) Squamous cell islets in gastric mucosa. 4) Differentiation ability of totipotent stem cells to other cell types.

Our knowledge about the management and prognosis of SCC of stomach is restricted because it is seen rarely. Primary treatment of the disease is surgery (10). Schmidt et al. (3) have reported 5 years survival without symptoms of the disease by the treatment composed of surgery, radiotherapy and chemotherapy (5-fluorouracil, leucovorin, cisplatin and etoposide). Yıldırım et al. (4) had achieved a 3 year remission in the SCC of stomach that had nearby organ invasion with the 5 -fluorouracil and cisplatin protocol.

Due to the inadequate number of reported cases, the efficacy of neoadjuvant chemotherapy and radiotherapy is unknown. Hovewer, as SCC of any other part of the body adjuvant chemotherapy and radiotherapy are primary mainstay treatment of the SCC of stomach.

\section{CONCLUSION}

The prevalence of SCC of the stomach is very low and it is an aggressive neoplasm as it metastasizes to the lymph nodes and the liver. We know that primary gastric SCCs are aggressive tumors due to higher incidence of lymphovascular and serosal invasion which are responsible for poor prognosis. Clinicians must be aware of all these.

Informed Consent: The patient's consent form of all treatment levels including medical and surgical treatment steps was taken routinely, however this article is written after all treatment and discharge of patient from the hospital. Thats why we did not need to prepare special consent form for the article.

Peer-review: Externally peer-reviewed.

Author Contributions: Concept - A.S., K.Ö.; Design - O.B.G.; Supervision - F.Ç., C.E.; Funding - E.Y.; Materials - K.Ö., F.Ç.; Data Collection and/ or Processing - C.E., H.Y.; Analysis and/or Interpretation - S.A.; Literature Review - A.S.; Writer - O.B.G., A.S.

Conflict of Interest: No conflict of interest was declared by the authors.

Financial Disclosure: The authors declared that this study has received no financial support.

\section{REFERENCES}

1. Callery CD, Sanders MM, Pratt S. Squamous cell carcinoma of the stomach: a study of four patients with comments on histogenesis. J Surg Oncol 1985; 29: 166-172. [CrossRef]

2. Muto M, Hasebe T, Muro K, Boku N, Ohtsu A, Fujii T, et al. Primary squamous cell carcinoma of the stomach: a case report with a review of Japanese and Western literature. Hepatogastroenterology 1999; 46: 3015-3018.

3. Schmidt C, Schmid A, Lüttges JE, Kremer B, Henne-Bruns D. Squamous cell carcinoma of the stomach. Report of a case and review of literature. Hepatogastroenterology 2001; 8: 1033-1036.

4. Yildirim Y, Akcali Z, Bilezikci B, Ozyilkan O. Primary squamous cell carcinoma of the stomach: a case report. Tumori 2005; 91: 440442.

5. Volpe CM, Hameer HR, Masetti P, Pell M, Shaposhnikov YD, Doerr RJ. Squamous cell carcinoma of the stomach. Am Surg 1995; 61: 1076-1078.

6. Parks RE. Squamous neoplasm of the stomach. AJR 1967; 101: 447-449. [CrossRef]

7. Boswell JR, Hellweg EB. Squamous cell carcinoma and adenocarcinoma of the stomach. Cancer 1965; 18: 181-192. [CrossRef]

8. Callacondo D, Ganoza-Salas A, Anicama-Lima W, Quispe-Mauricio A, Longacre TA. Primary squamous cell carcinoma of the stomach with paraneoplastic leukocytosis: a case report and review of literature. Hum Pathol 2009; 40: 1494-1498. [CrossRef]

9. Straus R, Heschel S, Fortmann DJ. Primary adenocarcinoma of the stomach, a case report and review. Cancer 1969; 24: 985-995. [CrossRef]

10. Little M, Munipalle PC, Viswanath YK. Primary squamous cell carcinoma of the stomach: a rare entity. BMJ Case Rep 2013; pii: bcr2013009706. 